\title{
China in a Post-Kyoto Architecture
}

Michal Meidan

\section{OpenEdition}

Journals

Édition électronique

URL : http://journals.openedition.org/chinaperspectives/1273

DOI : 10.4000/chinaperspectives. 1273

ISSN : 1996-4617

\section{Éditeur}

Centre d'étude français sur la Chine contemporaine

Édition imprimée

Date de publication : 15 janvier 2007

ISSN : 2070-3449

\section{Référence électronique}

Michal Meidan, "China in a Post-Kyoto Architecture », China Perspectives [En ligne], 2007/1 | 2007, mis en ligne le 08 avril 2008, consulté le 28 octobre 2019. URL : http://journals.openedition.org/ chinaperspectives/1273; DOI : 10.4000/chinaperspectives.1273

(C) All rights reserved 


\title{
China in a Post-Kyoto
}

\section{Architecture:}

\author{
Reconciling Internal and External Pressures
}

\author{
MICHAL MEIDAN
}

The questions of climate change and environmental protection are now a clear component of Beijing's official rhetoric. Already taken into account in the Tenth Five-Year Plan (2000-2005) with few concrete results, the reduction of greenhouse gas emissions, energy efficiency and conservation have become some of the leading priorities in the roadmap set down by the government for 2006-2011. Despite the scientific uncertainties surrounding the question ${ }^{(1)}$, there is no longer any doubt in China that the country's exponential economic growth is a major contributor to the degradation of the natural environment. ${ }^{(2)}$

$\mathrm{T}$ he protection of the environment may, finally, have reached the top of China's political and economic priorities. Beijing is declaring its readiness to commit itself to the international fight against climate change, but in what form?

In order to evaluate the role of China in a post-Kyoto architecture, it is necessary to analyse the diverse and sometimes contradictory pressures that are being exerted on it both nationally and internationally. Some of these pressures target the pursuit of economic growth as the first priority (represented by industrial interest groups and certain ministries at the local and national level): "energy security takes priority over climate security" (3). These pressures are, however, being attenuated by a concern expressed ever more strongly by the National Environmental Protection Agency, or NEPA, which became SEPA State Environmental Protection Agency-in 1998, by some researchers at government think tanksthe Chinese Academy of Social Sciences (CASS), the energy research centre affiliated to the National Development and Reform Commission (NDRC)-, by the environmental non-governmental organisations (NGOs) and the media. Finally, the efforts of the international community and of the international scientific communities are playing their part in advancing the environmental cause in China.

It is the power relationship between these different pressure groups that will, ultimately, determine the policies enunciated in Beijing. The question that has to be asked is thus the following: will China be able to translate its rhetorical prior- ities into concrete measures at the national level? On the international level, how does it see its role in a post-Kyoto order?

To assess these problems requires a more in-depth analysis of the origins of environmental policy in China and of the obstacles to its application, something which underlines the great difficulty that Beijing has in implementing its priorities. First of all, the weakness of the government actors charged with the environmental issue leaves them struggling to compete against the industrial interests. Second, as implementation of environmental policies is conducted primarily through political campaigns a practice strongly anchored in the tradition of environmental management ${ }^{(4)}$-and by means of administrative tools, it remains largely inadequate in getting local and industrial actors on board. Moreover, the framework convention on climate change necessitates adaptation of national legislation and the establishment of administrative mechanisms capable of achieving the objectives set, and its application depends to a large extent on internal processes of responsibility and reporting.

1. For more details on this debate, see David G. Victor, Climate Change: Debating America's Policy Options, Council on Foreign Relations, New York, 2004, pp. 8-19.

2. "China is determined to curb use of fossil fuels," www.zoomchina.com.cn, 6 February 2007, http://www.gasandoil.com/goc/frame nts news.htm, consulted on 1 March 2007.

3. Xuedu Lu, Jiahua Pan, Ying Chen, "Sustaining Economic Growth in China under Energy and Climate Security Constraints," China \& World Economy, vol. 14, n 6 , 2006, pp. 85-97.

4. Hyung-Kwon Jeon, Seong-Suk Yoon, "From International Linkages to Internal Divisions in China: The Political Response to Climate Change Negotiations," Asian Survey, vol. 56, n 6 , November-December 2006, pp. 846-866. 


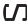

Finally, if the external pressures on China have in the past been effective to a certain extent ${ }^{(5)}$, it is nevertheless still true to say that any Chinese commitment to an international architecture remains fundamentally rooted in the belief that it must, first and foremost, benefit China's growth objectives, as Beijing considers that the current environmental situation is, after all, attributable to the developed world.

\section{Pressures in favour of} change - and resistance

\section{The evolution of "green" rhetoric and poli-} cies in China

The "green" debate is not a recent development in China. The initial primer for "environmental governance ${ }^{(6)}$ " dates back as far as 1972, the year when, following a series of ecological calamities in China, premier Zhou Enlai established a leading group with the aim of protecting the country's water reserves, but also in preparation for China's participation in the first United Nations conference on human environment (one year after China's accession to the UN). Two permanent committees for the protection of the environment were created under the aegis of the National People's Congress and under the State Council. Despite the existence of these committees as well as abundant legislation integrated in the constitution of $1982^{(7)}$, the protection of the environment remained a secondary priority, notably as a result of the weakness of the political and judicial bodies entrusted with its implementation. NEPA, created in 1988 under the State Council, was charged with the entirety of the environmental legislation, the drafting of administrative regulations and national standards, the management of pollution problems and the co-ordination with the United $\mathrm{Na}$ tion, but did not enjoy the benefits of a ministerial rank or of a sufficiently large workforce. Moreover, NEPA often had to negotiate with more powerful ministries that were promoting economic development, and had at its disposal few tools to translate its priorities into real measures, in the absence of a sufficiently powerful judicial system or market incentives ${ }^{(8)}$. More fundamentally and in the tradition of the great environmental campaigns in China, if the political campaign is not launched by the very highest political authorities ${ }^{(9)}$, the environmental cause will have little chance of getting anywhere.

\section{First changes}

Since the arrival in power of Hu Jintao and Wen Jiabao, environmental priorities have prominently featured in the official rhetoric and have been fully incorporated in the vision of what constitutes China's energy insecurity. Several factors have in fact contributed to placing these questions at the heart of Beijing's socio-economic priorities.

The question of the degradation of the natural environment is tightly linked to Chinese energy consumption habits: $70 \%$ of the primary energy of the country is supplied by coal, while a further $25 \%$ is covered by oil. Its energy consumption structure has propelled China to second place in the list of worldwide $\mathrm{CO}_{2}$ emitters behind the United States, but as of 2009, according to the International Energy Agency (IEA), China will sit at the top of the table of the world's polluters. Its $\mathrm{SO}_{2}$ emissions in 2006 amounted to 25,944 million tonnes, an increase of $1.8 \%$ from the previous year ${ }^{(10)}$, in terms of $\mathrm{CO}_{2}$, the country has gone from 2,289 billion tonnes of $\mathrm{CO}_{2}$ emitted in 1990 to 3,307 billion tonnes in 2002 (II), and 5,6 billion tonnes in $2006^{(12)}$.

Arable land in China is in constant decline, water pollution is reaching alarming proportions and the rare resources that are available are of poor quality: $70 \%$ of the water that flows into the five major rivers is dangerous for human consumption. Similarly, between 300,000 and 400,000 people die every year from respiratory problems, while seven of the ten most polluted cities in the world can be found in China ${ }^{(1)}$. The winter of 2006 was the hottest for 50 years ${ }^{(14)}$, following a constant trend over the last few years, which has led scientists to warn the authorities that a temperature rise on the Qinghai-Tibet plateau would alter the

5. Lester Ross, "China: Environmental Protection, Domestic Policy Trends, Patterns of Participation in Regimes and Compliance with International Norms," The China Quarterly, $n^{0} 156$, special edition, China's Environment, December 1998, pp. 809-835.

6. Elizabeth C. Economy, The River Runs Black, London, Cornell University Press, 2004, pp. 93-98.

7. For more details concerning the legislation, see Michael Palmer, "Environmental Regulation in the People's Republic of China: The Face of Domestic Law", The China Quarterly, no. 156, p. 788-808.

8. Ibid.

9. Hyung-Kwon Jeon, Seong-Suk Yoon, op. cit.; E. Economy, op. cit.

10. "Experts analyze increase in key pollutants during 2006", People's Daily Online, 13 February 2007, http://english.people.com.cn/200702/13/eng20070213 349778.html, consulted on 1 March 2007.

11. Vivien Wu, Ray Cheung, "Beijing likely to face more pressure to cut emissions Environmental movement will get new momentum", South China Morning Post, 17 February 2005

12. Brice Pedroletti, "La Chine devient championne du monde des émissions de gaz à effet de serre, " Le Monde, 24 May 2007

13. Jennifer L. Turner, Juli S. Kim, "China's Filthiest Export”, 7 February 2007, Foreign Policy in Focus, www.fpif.com, consulted on 20 February 2007

14. "Report says 2006 was China's warmest year in half a century", Associated Press, 20 February 2007. 
quantities of water that flow into the Yangtze and the Yellow River ${ }^{(15)}$ as the glaciers continue to melt.

The desertification and the erosion of arable land mean that sandstorms have become a regular occurrence in the Chinese capital, their effects even reaching Seoul and Tokyo since 2001. While massive reforestation programmes have somewhat moderated the rate of deforestation in China, the area devoted to arable land continues to diminish, something that is not without consequence for the country's food security. Pollution is said to cost China $8 \%$ to $12 \%$ of its GDP in direct losses: agricultural products damaged by acid rain, medical expenses, aid to victims of ever more frequently occurring natural disasters and costs engendered by the rarefaction of resources.

The problem of the degradation of the natural environment is not restricted to China's national borders, leading to rising international pressures for action ${ }^{(16)}$, and China, thanks to its contribution to pollution, cannot be excluded from any global arrangement.

The internal pressures in China echo the voices that are being raised internationally. The different Chinese NGOs as well as the organisations set up by the government for the protection of the environment have been among the only ones to obtain authorisation to work in China. With the creation of Friends of Nature, the first environmental NGO in China, in 1994, Beijing opened the door to these kinds of associations, but the government's ambiguous attitude towards them makes their activities difficult. Because of that, the different Chinese NGOs (Friends of Nature, Green River, Wild China, among others) maintain a delicate and sometimes tense alliance with the authorities, but avoid openly defying the policies decided on by the central government ${ }^{(17)}$. Nevertheless, the activists are gradually becoming more critical of the authorities and now have at their disposal an information and support network among the NGOs and the international media ${ }^{(18)}$. Even if they do not always obtain the desired results, these activists perform functions within the environmental protection system that are otherwise left unfilled by institutional gaps: supervising the execution of laws and regulations, and education in the field of environmental protection. They also allow the government to demonstrate a certain degree of political tolerance ${ }^{(19)}$. The support of the government for the NGOs thus remains partial: the restrictions imposed on the registration and financing of and employment at the NGOs have limited their number and their activities in China, but despite the risks that they might present for Beijing, they fulfil an important bridging function, with the particular encouragement of SEPA.

\section{The fourth generation sets out a new environmental commitment...}

A new perspective on energy security, expressed through the theme of the "conservation-minded society," (jieyuexing shehui) has emerged following the accession to power of $\mathrm{Hu}$ Jintao and Wen Jiabao. The two leaders initially introduced the concept of "scientific development," which seeks to balance economic development with its human and natural costs. Since then, this concept has been elevated to the rank of a doctrine and relayed to all levels of the state ${ }^{(20)}$. This new vision of development relies heavily on the development of technologies, on the energy savings generated by the transformation of the industrial structure and the reduction in energy intensity, on the education of the people and on the intervention of the state in the choice of investments. The emphasis has thus been placed, first and foremost, on measures aiming at improving the energy efficiency of the country, while relying on the gradual modification of its economic structure from a manufacturing industry, highly polluting and energy-consuming, to the services industry-and enhancing the energy-saving measures by raising standards, replacing old equipment and introducing more efficient technologies.

Since 2004, the losses in terms of natural resources have been estimated approximately thanks to the calculation of a "green GDP" that deducts the environmental costs from the traditional calculation of GDP ${ }^{(21)}$ and would thus allow local mindsets, up to now greedy for growth figures, to be changed. Finally, the Eleventh Five-Year Plan has introduced the very ambitious goal of reducing the country's energy intensity by $20 \%$ over the period ${ }^{(22)}$.

Several initiatives have also been launched in order to promote the introduction of renewable energy, to facilitate trade in carbon emissions rights and the Clean Development

15. Jo Johnson, Richard McGregor, "Dry reality - China and India face up to curbs on carbon", Financial Times, 27 February 2007.

16. Michael Richardson, "Watching through the haze", South China Morning Post, 15 July 2005.

17. E. Economy, op. cit., p. 136. The activities undertaken during the construction of the Three Gorges Dam were essentially initiated by international NGOs.

18. Ibid.

19. E. Economy, op. cit., p. 173-175.

20. Joseph Fewsmith, "Promoting the Scientific Development Concept", China Leadership Monitor, no. 11 (2004), http://www.chinaleadershipmonitor.org.

21. Thibaud Voïta, "Le PIB vert, si proche et si loin", China Analysis, n 9, October 2006.

22. "China sets major goals for 11th Five-Year Plan period", People's Daily, 13 October 2005, http://english.people.com.cn/200510/13/eng20051013 214194.html, consulted on 27 February 2007. 
Mechanism (CDM) established by the Kyoto protocol, for which 300 projects were reportedly launched by January 2007. In the fight against atmospheric pollution generated by the use of coal, the NDRC is planning to gradually shut down small thermal power stations in the country. China relies on these thermal power stations for $82 \%$ of its electricity, but the majority of them are inefficient and polluting ${ }^{(23)}$; furthermore, a large number of them were built without approval and often in contradiction with the priorities enunciated by the central government. This approach of the NDRC forms part of a series of initiatives formulated in January 2007 by the central government in order to reduce the country's coal consumption by 2010 .

At the national level, the fight for environmental protection has been launched both in rhetoric and in practice. China is creating funds to finance "green" projects, to encourage research and development of new technologies, to reduce the emission of pollutants, to progressively organise a trading system in emission permits ${ }^{(24)}$ and to help increase the country's arable land. Beijing has also strengthened the legal establishment with regulations concerning the use of dangerous materials by industry and the Renewable Energy Law (2005), which should allow an increase in the share of renewable energy in the country's energy consumption.

\section{... not without difficulties}

Despite the efforts to raise awareness, the public campaigns and the amended laws, China will have trouble reaching the goals set by the Eleventh Five-Year Plan. The goal of reducing energy intensity by $20 \%$ already seems impossible to achieve $^{(25)}$, and the central government is finding it difficult to impose its priorities on all provinces.

It is true that such a radical transformation of the structure and model of economic growth may well be difficult to implement so fast in China. Beyond the redefinition of priorities, numerous fundamental obstacles prevent progress to more efficient energy consumption and to the adoption of energy-saving measures that can be applied on a national scale, particularly the absence of a legal tradition and market mechanisms ${ }^{(26)}$. As long as the price of energy products remains controlled and maintained artificially low by Beijing, it will be difficult to introduce new sources of energy. Similarly, environmental legislation in China remains incomplete and difficult to apply (as is the case, for example, with the Renewable Energy Law) ${ }^{(27)}$, few regulations and standards have been formulated and the current legal body seems more like a general roadmap than operative laws.
Civil participation, despite the activity of the NGOs, remains limited, and the protection of the environment is perceived as a problem of rich countries, or in the case of China, of well-off provinces ${ }^{(28)}$. It is nevertheless still true that the environmental protection initiatives are political and administrative, favouring a rationale of political campaigns. Because of that fact, at the local level, the priority of economic development at all costs remains de rigueur, even more so as the cost of non-compliance with environmental objectives remains very low for the public actors ${ }^{(29)}$.

Finally, even within the leadership, the commitment to environmental protection remains nuanced; while environmental protection and participation in international mechanisms are priorities for Beijing, their importance should not be overestimated. The pursuit of the country's economic development cannot be allowed to suffer from it.

\section{The role of external pressures}

Despite the national difficulties in translating the initiatives into applicable measures, the international community and the international mechanisms in which China participates exert a supplementary pressure on the Chinese decisionmakers. Since 1972, when China took part in the first UN conference on Human Environment, the Chinese leadership has set up specialist teams within NEPA, the Ministry of Foreign Affairs and the scientific community to represent China at these international forums and help accommodate them in national policies. China's environmental diplomacy is thus strongly influenced both by these external pressures, by the internal power relationships within the country, and by the way in which China sees its place and its role in international efforts.

\section{The origins of China's environmental diplomacy}

The timid beginnings of China's environmental diplomacy can be traced back to the 1970s with its guarded member-

23. “Just hot air?”, The Straits Times, 4 February 2007.

24. "China mulls new measures in environmental protection”, Xinhua, 20 February 2007.

25. Ding Jun, Wang Shiling, "Reducing energy intensity by $20 \%$ : the goals will not be met," 21 Shiji jingji baodao, (Chinese) 14 September 2006.

26. Hyung-Kwon Jeon, Seong-Suk Yoon, op. cit..

27. Interview with a researcher at Tsinghua University, January 2007.

28. Zhou Jigang, meeting with Pan Yue, "The Rich Consume and the Poor Suffer from the Pollution," 21 Shiji jingji baodao, 27 0ctober 2006 (Chinese).

29. Hyung-Kwon Jeon, Seong-Suk Yoon, op. cit.. 
ship of a number of environmental forums. It was not, however, until the 1980s that the commitment became more active with the signing of over fifty international environmental treaties, including more than fifteen conventions and 27 bilateral agreements ${ }^{(30)}$. China has progressively developed close ties with scientific and political communities throughout the world. However, in the same way that it has encountered difficulties in gaining compliance with its national regulations, the implementation of international initiatives has been partial, as much because of the internal pressures, mentioned earlier, as because of a preference to limit its commitment to international environmental mechanisms to the extent that they risk slowing down the rate of the country's growth. China has in fact preferred to maximise the benefits drawn from the "public good" in question while minimising the constraints and limitations that are exerted on the country's political choices ${ }^{(31)}$. According to Johnston, if Chinese diplomacy favours the pursuit of unilateral interests (judging that these are often incompatible and irreconcilable with multilateral interests), their pursuit at any price is moderated by the need to preserve a favourable image of the country. While Johnston's analysis remains pertinent today, one nuance should be introduced, for China is now more familiar with the multilateral forums and thus less distrustful of them than was previously the case. There is no longer such a clear distinction between unilateral (national) and multilateral interests, the number of international organisations of which the country is a member has grown, and the experience, in particular in the World Trade Organisation, has ultimately proved a positive one, in spite of the apprehensions at the time of China's accession ${ }^{(32)}$. It is nevertheless still true that Chinese participation in these forums, although more active than in the past, aims first and foremost at preserving its national interests, such as they are perceived by the leading circle, and with promoting an image of a responsible country. While this concern with image guarantees China's participation in the multilateral efforts, it does not, however, ensure that China will take on an active or dominant role in the promotion of interests to which it does not fully adhere. In order to understand better the limits of any possible role it might play, it is necessary to examine China's motivation as well as the interests that are at stake.

\section{Constant principles}

From the first negotiations on the United Nations Framework Convention on Climate Change, Beijing has highlighted certain principles, defended more or less virulently over the years ${ }^{(33)}$, perhaps the most notable of which is the principle of sovereignty and the right of the country to utilise its natural resources for its development without outside interference ${ }^{(34)}$. This approach makes it difficult not only to adopt constraining commitments concerning the methods of exploiting natural resources and emissions, but, implicitly, also the work of reporting and of evaluating progress, especially given that the role of the NGOs, which are supposed to fulfil this function, is limited.

Secondly, economic growth continues to be a top priority of the Chinese government. Although Beijing affirms the importance of moderating the natural and human costs of the current growth mode and rate, China has preferred to let other international actors contribute more to this public good so that it can extract the benefits while making a minimal contribution. This approach is also justified by the decisionmakers with the affirmation that the degradation of the global environment is primarily due to the industrialised countries which exploited natural resources extensively during their economic development. If the "polluter pays," it would thus be up to the developed world to bear the majority of the costs and clearly to take the lead in any commitments undertaken ${ }^{(35)}$. On this point, the Chinese position has been constant ever since the first negotiations in 1992, and the American refusal to ratify the Kyoto protocol in 2005 has indeed reinforced it, as it was perceived as a manifestation of the weakness of the West's commitment.

In terms of image, this position, which has been more extensively adopted by the Group of 77 (G77), allows China to promote its image as a champion of the developing world.

30. Hyung-Kwon Jeon, Seong-Suk Yoon, op. cit.

31. Alastair lain Johnston, "China and International Environmental Institutions: A Decision Rule Analysis", in McElroy, Nielsen, Lydon (eds.), Energizing China: Reconciling Environmental Protection and Economic Growth, Cambridge, Harvard University Press, 1998, p. 558.

32. Shi Dian, "Five Years After China's Accession to the WTO", 21 Shiji jingji Baodao, 14 December 2006 (Chinese); Hu Shuli, "The WTO After Five years", Caijing, n 172, 21 December 2006 (Chinese).

33. Chayes and Kim note an evolution of the Chinese position between the negotiations of the intergovernmental negotiating committee in February 1995 and the first conference of the parties, held in March and April 1995, but this change is rather one of form: in February 1995, China actively defended the position of the developing nations while two months later it supported more discreetly the efforts of India, thus positioning itself in the end as a moderator between the developed and the developing worlds. It would not seem, however, that China has given ground on the principles to which it has held. See Abraham Chayes, Charlotte Kim, "China and the United Nations Framework Convention on Climate Change", in McElroy et al., Energizing China, op. cit., pp. 503-531.

34. Hyung-Kwon Jeon, Seong-Suk Yoon, op. cit..

35. Zhang Zhongxiang, "Reconstructing Climate Policy: How Best to Engage China and Other Developing Countries", East West Center Study Draft, May 2003.

36. Ibid. 


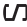

While China is rapidly joining the ranks of polluters, and should thus bear the cost of that, Chinese diplomacy draws a distinction between "survival emissions" and "luxury emissions ${ }^{(36) .}$

In sum, the role of this environmental diplomacy has to date been to avoid high-cost commitments, in particular any imposition of emission quotas, targets and ceilings, all the while providing more signs of greater activity as far as that is possible. Between 1990 and 1994, China hosted at least eighteen international conferences on the subject and signed and ratified all the international agreements on the environment.

\section{Conditional participation}

China is indeed active in the international forums on climate change, all the more so as any arrangement for a post-Kyoto architecture will inevitably place more constraints on developing countries. How to reconcile, then, the image of a responsible country with its hesitation to deliver on concrete targets for the reduction of emissions?

There is a chance that China's position will evolve very little, particularly on its insistence to see developed countries bearing the costs. But the American refusal to ratify the Kyoto protocol will persist as long as there is no firm commitment of the developing nations, and China in particular, nor any constraint on them. This vicious circle could be interrupted, however, especially with the change of administration in the United States in 2008. The refusal to ratify the Kyoto protocol does not represent a fundamental rejection of the problem of climate change, the United States being a signatory to the United Nations Climate Convention, which came into force in 1994, and it is as a signatory of this convention that the United States takes part in the conferences on Climate Convention and on the Kyoto protocol. How to reconcile American environmental policy with that of China should therefore form part of the questions broached in the strategic dialogue between the two countries. This is not an impossibility, and the prospect of a jointly elaborated architecture cannot be ruled out, particularly in a relatively favourable bilateral political context, and in light of the creation in July 2005 of the "Asia Pacific Partnership on Clean Development and Climate" (AP6), announced on 12 January 2006. This partnership brings together Australia and the United States (neither of whom have ratified the Kyoto protocol), India, Japan and South Korea. In contrast to the Kyoto protocol, the partnership does not provide for any mandatory targets for the reduction of emissions or for any restrictive application mechanisms; each country is free to decide its own targets.

Similarly, the turnaround taken by President Bush in his annual address to the US Congress ${ }^{(37)}$ has put the question of climate change back on the international agenda. Although the priority advertised by the United States concerns energy independence, the introduction of new technologies and clean energy sources (and not a volte-face on Kyoto), this change of tone has succeeded in producing a new declaration at the G8 summit, in the presence of representatives from China, India, Brazil, Mexico and South Africa, concerning the creation of a global $\mathrm{CO}_{2}$ emissions market ${ }^{(38)}$. While this declaration is not in any way restrictive or operative, it does mark the beginning of negotiations on the architecture of a future agreement, albeit still allowing for a weakening of the Kyoto protocol framework.

In the same way, China will be reluctant to accept emission quotas it has so far refused to adhere to them unless the calculation of the level of emissions were based on a per capita calculation, given that its per capita emissions are low, and unless the emission targets were calculated as a function of future growth and development prospects ${ }^{(39)}$.

The negotiation process promises to be long and complex; China will perhaps moderate its positions but will be highly reluctant to abandon its underlying positions, in particular in view of its image within the G77. The imposition of emission quotas and any concerted action aimed at changing the structures and the modes of the Chinese economic system may become a major point of contention. However, changing the level of quotas could be acceptable for China, with a transition from an initial period of non-binding targets to a higher and more solid commitment in a second phase. China would, no doubt, like to limit the international agreements to a regime that would facilitate concrete co-operation as well as funds intended to promote research and development in the field of new energy sources and for the introduction of renewable energy. But in the absence of other alternatives, and not wishing to withdraw from the negotiations on the Kyoto protocol, China would make concessions, while attempting to reduce these to a minimum. A progressive approach could thus moderate Chinese reticence, on

37. Cf. http://www.whitehouse.gov/news/releases/2007/01/20070123-2.html.

38. "Politicians sign new climate pact," BBC World Service, 16 February 2007.

39. Zhang Zhongxiang, op. cit.. The emissions for the countries in Annexe B are calculated on the basis of past levels. With the standard of living in the developing nations still low, the emission quotas should, according to China, take into account the pursuit of economic development and future needs, which remain, however, difficult to evaluate. 
condition that the United States also takes part, and that the new architecture allows a progressive and joint elaboration of more long-term targets ${ }^{(4)}$. Moreover, if alternatives to Kyoto that are viable and more beneficial to China exist (such as the AP6 for example), China could withdraw from any agreement, judged to be too restrictive.

The question of time remains key, however. In the course of the three decades that have elapsed since the first UN conference, the tools of environmental policy in China have undergone a considerable evolution in terms of scientific and legal expertise and know-how, allowing the consolidation of a regulatory framework, the creation of a community of ex- perts and exchanges with their foreign counterparts to deepen. The role of the NGOs, with all the related difficulties, is playing a part in changing mind-sets and in giving rise, timidly and gradually, to civil participation.

If few concrete results can be foreseen before the change in the American administration in 2008, it may well be that the real evolutions in China will have to wait for the advent of the "fifth generation" of leaders in 2012. At present, the external pressures, as influential as they may be, are still limited by internal resistance. $\bullet$

\section{- Translated by Nick Oates}

40. See also Sheila M. Olmstead and Robert N. Stavins, An International Policy Architecture for the Post-Kyoto Era, AEl-Brookings Joint Center for Regulatory Studies, January 2006. The study proposes a gradual and evolving architecture that could provide more flexibility. However, one of the principles is the introduction of policy tools made up essentially of market mechanisms, a point that remains difficult to apply in China. 